\title{
Maintenance Epistemology and Public Order: Removing Graffiti in Paris
}

Jérôme Denis \& David Pontille

Centre de Sociologie de I'Innovation

I3 (CNRS UMR 9217) - Mines ParisTech

PSL Research University

jerome.denis@mines-paristech.fr

david.pontille@mines-paristech.fr 


\begin{abstract}
Taking part in the growing concern for repair and maintenance in STS, this article investigates epistemic dimensions of maintenance. Drawing on an ethnographic study of graffiti removal in Paris, it highlights the different objects of knowledge involved in this specific setting of urban maintenance and documents their relationships. It shows that, inspired by the 'broken windows' thesis, the anti-graffiti program that emerged in Paris at the turn of 2000 articulates three objects of knowledge - public order, graffiti and the city whose intertwined definitions root a restorative maintenance epistemology. Such epistemology unfolds in an assemblage of policy documents, regulatory texts, contracts, technical specifications and procedures, information infrastructures and categories, removal techniques, tools and situated gestures, which take place in municipality's offices, contractors' workshops and during each intervention in the streets. The Paris graffiti removal program instantiates a preservationist approach which focuses on recurrent visual signs of disruption occurring on the façades and rests on both a distributed attention and a particular pace for interventions. It involves three main operations: measuring surfaces, identifying public expressions and composing with materials. None of these operations are neutral. Aimed at preserving a specific order, they also participate in the daily transformation of urban reality. The heterogeneous knowledge at play in maintenance practices intricately takes part in the becoming of the things whose stability it strives to ensure.
\end{abstract}

\title{
Keywords
}

maintenance $\cdot$ graffiti $\cdot$ city $\cdot$ knowledge $\cdot$ material ecology $\cdot$ neglected work $\cdot$ urban order

\section{Author biographies}

Jérôme Denis is Professor of Sociology at the Centre de Sociologie de l'Innovation, Mines ParisTech. His research focuses on data labor in various organizational environments, and maintenance practices. He is the co-founder of Scriptopolis, a collective scientific blog about writing practices (http://www.scriptopolis.fr/en).

David Pontille is senior researcher at the French National Center for Scientific Research. His research focuses on the evaluation technologies of scientific research, and maintenance practices in urban settings. He is the co-founder of Revue d'Anthropologie des Connaissances, and a collective scientific blog about writing practices: Scriptopolis (http:// www.scriptopolis.fr/en). 
In recent years, the City of Light seems to have been relatively unaffected by graffiti. Far from reflecting an urban order stabilized once and for all, this is the result of ceaseless work. Every morning in Paris, workers remove graffiti from building façades, while others patrol the streets, scanning for unsolicited inscriptions on the walls. As part of an anti-graffiti policy, such daily work has been carefully organized and outsourced since 2000 . As mundane as it may seem, this policy is particularly ambitious in terms of public order. This is what we understood one day during an interview with a municipality's technical manager, who has been involved in the graffiti removal program since its very beginning. After having discussed at length the transformations in the work organization, the tools and techniques, we concluded the interview on the current challenges the unit was facing. As we were about to leave, in front of his office, our informant made a last argument to justify his activity, pointing to what he considered its origins: 'You know, it all comes from New York City. Everything we've been doing in Paris since 2000 is in the name of the broken windows theory' (Larry, technical manager of the Paris graffiti removal team, February 21, 2017).

Although seemingly anecdotal in a long-term investigation like ours, this clear statement, coming from a technician, struck us as particularly important. First, and this was not a huge surprise at this point of our enquiry, it explicitly links the routine work of removing graffiti to public order and its maintenance. As we describe below, the so-called 'broken windows' thesis was first coined by a professor of government at Harvard and a former policeman (Wilson and Kelling, 1982), who aimed to rethink the way public order was dealt with by police forces. In recent years, an emerging research domain has questioned the relationships between social and political order and maintenance practices (Denis and Pontille, 2015, 2020; Graham and Thrift, 2007; Henke, 2000; Jackson, 2014; Strebel et al., 2019), and has emphasized the always incomplete and ongoing processes through which order is performed. For instance, Henke $(2000,2017)$, drawing on dynamic conceptions of shared orders (e.g. Goffman, 1959; Garfinkel, 1967), analyzes the connections between the social and material forms of orders in the workplace, contrasting maintenance and transformation as two modes in tension between existing orders and contested futures. Investigating the maintenance of Egypt's irrigation infrastructure, Barnes (2017) shows how the dramatic maintenance operations on a canal in the province of Fayoum were key in reinforcing a specific material and social order, putting aside illicit practices, attributing specific places to farmers own maintenance activities and reasserting the engineers' authority and control over the infrastructure. In his study of the transformation of Lenin's body into a long-term living sculpture, Yurchak (2015) points out how far the material and physical orders involved in these preservation practices had been tightly articulated to the political order, notably the canonization of the Leninism. In a very different setting, Shaw (2014) documents the urban reordering process at stake in the street-cleaning practices in downtown Newcastle at night, progressively transforming some varied elements of the lively nightlife center into waste that disappears from the public space of the city by daytime.

Although extremely heterogeneous, these investigations all bring to light how a 'highly' political concern such as the stability of public order is embedded in concrete, though generally unnoticed, situated activities. These activities involve a variety of material components, including the bodies of maintenance workers themselves, whose daily reiterated gestures enact an ongoing and always provisory sociomaterial order. This is exactly what our informant was telling us when mentioning the 'broken windows' theory: The contracts we had read, the meetings we had attended, and, most of all, the removal operations we had observed, were all participating in the daily production of a specific order in the streets of Paris. But if his statement was obviously - at least to us - connected to 
these familiar research questions, it also pointed to an aspect that is less problematized in the emerging maintenance and repair studies. This is the second thing that struck us in our informant's assertion: Removing graffiti in Paris is directly connected to a theory. This means that maintenance, which is of course political, is also a matter of and for epistemology. This is the thread we would like to explore in this article, following Puig de la Bellacasa (2012: 199), who reminds us that 'creating knowledge is a relational practice with important consequences in the shaping of possible worlds'. Paying careful attention to the various ways in which knowledge is developed on and through maintenance is a way to better understand its ontological implications (Denis and Pontille, 2017), and to become aware of the things that are enacted and the worlds that are enabled through and by maintenance.

Before we go further, we need to make two clarifications. First, in line with early laboratory studies, we do not consider epistemology as a set of abstract theoretical principles about knowledge (Knorr-Cetina, 1981; Latour and Woolgar, 1979). Epistemologies are plural and always made of very concrete documents, gestures and ordinary practices accomplished in specific circumstances. A significant way to investigate it properly is to carry out what Dear (2001) calls 'epistemography', namely an effort to situate a fundamental epistemological topic and to trace its forming and composite presence in a given setting. Adopting this conception, we explore the epistemology of the Paris graffiti removal program through concrete practices that can be empirically investigated in a diversity of sites. This means we not only study how the 'broken windows' theory is connected to graffiti removal activities, but also explore the knowledges and 'ontological enactments' (Woolgar and Neyland, 2013) that occur in offices, workshops and in the streets.

Second, we do not seek to define maintenance as a global and uniform phenomenon. We think there is no single, homogenous way for things to be maintained. As shown in the growing variety of cases investigated in the recent literature, maintenance and repair practices involve distinct technologies, skills, political choices, gestures, know-how, guidelines, doctrines, and more. All of these components can be assembled differently according to settings and local situations. In short, as modes of orderings may differ (Law, 1994), a variety of modes of maintaining can be found in different configurations, and may even coexist (Denis and Pontille, 2017).

These two clarifications mean that we don't pretend to provide an exhaustive description of the epistemics of the 'broken windows' thesis in general (we think no such thing exists, actually), but we aim at understanding the specific kind of maintenance that is performed through a situated and composite epistemology in which some instantiations of the 'broken windows' thesis take an important part.

To do so, we stick to a very simple explorative question derived from the material semiotics of Akrich (1992): what matters? What counts for graffiti to be removed from building façades? And, by the way, what is graffiti? And what are building façades? By tracking down the concrete answers to these questions provided in legal documents, regulatory texts, contracts, technical specifications, and assertions (and sometimes gestures) in offices or streets, we show that the Paris graffiti removal program instantiates a preservationist approach of public order in the city. Such an approach focuses on visual signs of disruption and organizes a specific kind of urban maintenance in which building façades are daily taken care of through a distributed attention and a particular pace for interventions around three main operations: measuring surfaces, identifying public expressions and composing with materials. 


\section{Studying graffiti removal in Paris}

From December 2016 to June 2019, we carried out ethnographic investigations on Paris's graffiti removal policy. During our fieldwork, we gathered a series of documents whose terms and formulations have been carefully analyzed: municipal ordinances, calls for tenders, contracts, the mayor's speeches to the city council, and more theoretical texts. This inquiry gave us access to the categories, words and principles articulated in a doctrine of what graffiti, the city and the urban order is and should be.

Simultaneously, we complemented this set of documents by conducting interviews with various actors involved in graffiti removal within the municipality (two people responsible for graffiti removal at the Cleanliness and Water Department, and three people from the graffiti removal team within the department dedicated to cleanliness in Paris), and the two main companies (four people in management and two technical managers). Providing some insights into the organization of graffiti removal in the city (from the division of labor and the distribution of tasks to the equipment and techniques used), these investigations also informed a part of the genesis of the graffiti removal program, notably its epistemic roots, as it operates today and of its mutations.

In order to extend our inquiry into what matters in removing graffiti in Paris, we made direct observations of the removal interventions by shadowing five operators throughout their working day. We also participated in two monthly inspections during which representatives of the municipality and companies' managers collectively verify in the streets whether the contracted activity has been performed appropriately or not. Through the systematic use of photography, and of audio recordings when possible, these investigations allowed us to pay attention to the words used in daily practices to discover the techniques at play and to grasp the embodied part of graffiti removal.

\section{Visual signs of public disorder}

Previous studies have already shown the strong links between understandings of graffiti and the 'broken windows' thesis, especially in US cities (Austin, 2001; Shobe and Banis, 2014; Stewart and Kortright, 2015). A powerful way to link the discourse of disorder to the urban landscape, this theory has been analyzed as constituting the core of anti-graffiti rhetoric, which 'provides much of the epistemic foundation for the anti-graffiti efforts orchestrated by officials in New York City' (Kramer, 2010: 303). Generally described as an epistemic 'framework', the thesis problematizes public order by focusing on normally insignificant infringements that nonetheless endanger urban territories.

The general statement was put forward by Wilson and Kelling (1982), in a paper entitled 'The police and neighborhood safety: Broken windows'. Addressing the issue of public order in relation to police work, they claimed that police strategy should partly shift from the fight against major crimes toward an 'order-maintenance function' performed by foot police patrols. Their emphasis on presence in the streets was closely linked to what they considered the success of order-maintenance resulting from the prompt and repeated handling of infringements, however minor at first sight. To clarify why day-to-day order maintenance matters, they relied on a psychosocial experiment conducted in the 1960s by Philip Zimbardo, showing that an automobile with no license plates parked in a Bronx neighborhood was progressively dismantled shortly after its abandonment. Wilson and Kelling also referred to a seminal policy paper by Nathan Glazer discussing the effects of 
graffiti on subway trains in New York City - which has been retrospectively conceived of as a relevant testbed for the theory.

The subway fought a preliminary skirmish with disorder, a skirmish important because it validated important parts of the Broken Windows thesis, because it demonstrated that disorder can be conquered, and because it taught us a great deal about how to right disorder on a broader front. (Kelling, 1991)

The authors drew two main conclusions from these experiments. First, public order is a matter of visibility. Some visible phenomena in the public space work as 'signs of official failure' (Glazer, 1979: 4). This is the case for broken windows, litter and graffiti. Clear evidence of the absence of public authority, these phenomena that are not dangerous in themselves produce the image of 'a city apparently out of control' (Glazer, 1979: 8). They should be eradicated, Wilson and Kelling held, because they support a widespread feeling of insecurity that undermines the economic and social quality of community life. Second, these symptoms should be treated urgently because they are contagious. '[l]f a window in a building is broken and is left unrepaired, all the rest of the windows will soon be broken' (Wilson and Kelling, 1982: 31, emphasis in the original). Understood as signs that 'no one cares', each single instance of broken urban furniture and each piece of graffiti is seen as an encouragement that may lead to a multiplication of other cases. Each occurrence of these minor offenses must therefore be treated as a possible first step towards the decay of the social order. In short, according to this thesis, any disruption in the visual signs of physical order in public spaces 'could lead to the general collapse into lawlessness' (Austin, 2001: 146).

Though the theory remains clouded by uncertainty and has been the subject of debates (e.g. Kramer, 2012; Shobe and Banis, 2014), it gave a name to a solution some had already suggested at the end of the 1970s to address New York City's image problem (Austin, 2001: 140-146). Moreover, its main rhetorical principles have been reiterated in public statements by political elites and in the mass print media in New York since the 1970s. Indeed, the 'broken windows' thesis has regularly inspired and justified policing campaigns to rid graffiti of New York subway system, such as the 'Clean car program' implemented by David L Gunn in the 1980s (Austin, 2001). More broadly, it has justified campaigs to address incivilities that negatively affect the quality of life throughout the city, such as the zerotolerance policy initiated by Rudolph Giuliani in the 1990s (Kramer, 2012). Based on an unwavering intolerance of minor infringements committed in public space, this policy was quickly exported to other American cities, and became an international model for urban security.

By pointing to graffiti among the potential signs of disorder, the 'broken windows' thesis has instantiated a preservationist approach to public order akin to the one that used to drive heritage building conservation before the 1960s (Brand, 1994; Jones and Yarrow, 2013), or the defense of 'wilderness' among environmental conservationists (Callicott and Nelson, 1998). Mirroring the disorder caused by invasive species and reckless practices lies threats to a stable, peaceful urban reality that can be restored. This is particularly clear in the case of Paris. In 1999, Jean Tiberi, then mayor of the city, made the fight against graffiti a top priority. Explicitly finding his inspiration from the US and the 'broken windows' thesis, he initiated an ambitious program made public through a press release for the 'graffiti removal' pre-council conference, 26 January 2001 . This program went through a call for tenders in which a first operation was identified as the 'clean walls operation'. A twofold phase, this 
operation started with the setting up of a 'graffiti observatory' responsible for carrying out an inventory of the situation, followed by a massive removal campaign aimed at eliminating 'at least $90 \%$ of the graffiti detected at the origin of the contract' during the first twelve months. What was at stake there was made clear: a life without graffiti. The city had to be brought back to its initial, almost natural, state. Yet, such a preservationist approach cannot stop at this first gesture. This is the very content of the 'broken windows' thesis, especially when it comes to graffiti removal programs: The order has to be maintained on a daily basis.

\section{Daily maintenance for graffiti-free cities}

In New York City, the struggle against graffiti that began in 1972 initially took the form of a series of policies, technical innovations and removal programs set up to completely eradicate graffiti from subway cars (Austin, 2001; Castelman, 1982). None of these programs have proven successful. As these expensive initiatives were failing, the idea of a total extinction of graffiti was gradually abandoned by the Metropolitan Transit Authority in favor of 'normal graffiti maintenance' (Castelman, 1982: 157). This inclusion of graffiti removal in routine maintenance activities had two main consequences. First, graffiti removal was demarcated from the direct repression of graffiti writers, making graffiti removal a pivotal activity as such, parallel to the activities of police squads. Second, it directly linked graffiti removal to the principles of the 'broken windows' thesis. Rather than bringing things 'back to order' as a single massive action, graffiti removal programs explicitly acknowledged that, 'to maintain the aesthetic order of shared public space' (Austin, 2001: 146), repeated daily interventions were required.

In Paris, the program initiated by Tiberi was conceived as a matter of maintenance from the very beginning. Exclusively focused on unsolicited public inscriptions, the program was independent of the legal and police struggles against graffiti writers (which were not managed by the municipality of Paris), and explicitly left aside the prosecution of graffiti's authors. The first call for tenders stipulated that the 'clean wall operation' would be followed by a second phase, called 'maintenance', 'during which the result achieved shall at least be maintained', as stated in the press release for the 'graffiti removal' pre-council conference, 26 January 2001. Inaugurated on $2^{\text {nd }}$ February 2001, this phase consisted in removing any new graffiti detected during the following five years. From then on, this phase has been repeatedly renewed through calls for tenders every two to five years. Through this program, graffiti removal in Paris has thus been made a long-term process, explicitly articulated as a maintenance practice. ${ }^{1}$

Maintenance articulates here a specific definition of, and bodies of knowledge on, graffiti, urban reality and public order. At the center of this lies the city's walls. Both privileged sites of operations and the very objects of preservation, building façades have been directly affected by the program.

\section{Facades as an object of preservation}

Before the 'clean walls operation' launched in 1999 in Paris, cleaning was an obligation of every building owner, who were to pay for the interventions of the municipal graffiti removal

\footnotetext{
1 As in other cities around the world (Kramer, 2017; Ross, 2016; Young, 2010), parallel to this removal program, successive cultural initiatives have been developed to create spaces for graffiti and to promote street artists in Paris (Vaslin, 2017).
} 
team, either on a case-by-case basis or on an annual fee basis. With the graffiti removal program, the Paris building façades have been officially redefined so as to ease contractors' access to property owners' walls. On 15 October 1999, the city issued a municipal by-law that transformed their status to ensure that graffiti can be removed quickly and methodically, avoiding any litigation. The article 1 of this by-law specifies:

As of $1^{\text {st }}$ January 2000 , the City of Paris shall ensure, free of charge ... the removal, from Paris buildings, of graffiti visible from the public highway, including on the curtains of shops visible outside opening hours. (Paris City Hall by-law, October 15, 1999, Article 1)

With this by-law, the municipality can directly access private building walls without having to obtain the authorization, even tacit, of the owners. Reluctant owners can still refuse any proactive intervention by signing a discharge. It is then up to them to assume the removal of graffiti whose prolonged presence on the façades remains illegal.

Such a juridical move has been pivotal in the turning of Paris's private building façades into a collective object of endless maintenance work, involving thousands of interventions per year. Even if any façade is 'legally suspended between the protection of within and the regulation of without' (Andron, 2018: 213), the Paris municipal by-law indicates how much the image of the City of Light is of crucial concern. Of course, writing or scratching a surface does not merely alter it materially, because it simultaneously violates the idea of private property. But there is more. As for the subway cars in New York City, on Paris façades 'graffiti evokes defacement whereby the writing on a wall is also a scarring on a face. Here people equate surfaces of cars with the surfaces of their faces' (Smith, 1985: 90). Almost considered as important as face-work in social interaction (Goffman, 1959), the Paris façades have been raised to a public, figurative object to be cherished, requiring a careful attention and continuous maintenance. Free of graffiti, they display a cleaned environment that stabilize a specific kind of 'aesthetic order' (Ferrell, 1996), meant to manage the impressions of the local residents and to foster tourism attraction. Legally and aesthetically, if not morally, configured as an object of maintenance, building façades have been at the centre of a renewed attention.

\section{A distributed attention}

Even if the 'broken windows' thesis has not been fully empirically grounded, it is intimately tied to a set of material practices and procedures. While Wilson and Kelling (1982) called for foot police patrols to be assigned to local communities to secure order through vigilance, the Paris graffiti removal initiative has been organized with a particular distribution of attention to unsolicited inscriptions.

As in New York since the 1980s (Austin, 2001), Paris residents were made aware of the graffiti removal program through extensive media coverage. Building owners were sent an information leaflet, and any Parisian can be actively involved in the direct reporting of graffiti on their façades, either by calling a toll-free number or by filling in a dedicated form, available online on the Paris City Hall website. From 2013, a mobile app, 'InMyStreet', has been added to the reporting techniques for anomalies observed in urban spaces, including graffiti.

However, the innovative part lies elsewhere. In Paris, the ambitious program implemented by the Tiberi administration has endorsed the end of exclusivity of the city's cleaning services over graffiti removal that started with previous administrations. It first took the form 
of a call for tenders, which was won by a company that had been created for the occasion. Gradually, more companies were involved, competing to manage the different areas ('lots') into which the municipality eventually partitioned the city. Since February 2001, the contracts signed by the municipality and the companies have been performance-based, with the objective of maintaining the graffiti presence on Paris building façades under a maximum threshold. Still, the scope of the work has been extended from one call for tenders to the next. In addition to graffiti on façades, since 2006 billboards and stickers have been included as part of the removal program, and in 2012 urban furniture was added. In the most recent call for tenders, in 2018, some kiosks and the equipment of children's playgrounds and public gardens joined the entities that deserve a special attention.

Despite such an extension of the scope of companies' interventions, the city's cleaning services are still involved in graffiti removal. A city team is responsible for locations not included in the contracts, such as municipal buildings, public edifices, stadiums and schools, the banks of the Seine and walls along the ring road. This city team also works with the contracted companies, in particular during events such as elections or demonstrations that regularly come with a real writing outbreak in the city.

The Paris graffiti removal program establishes a particular division of labor, within which the components of urban spaces are shared between a graffiti removal municipal team and the contractors. Depending on the location of graffiti in the urban environment, one or the other is in charge. Not only does this spatial allocation define distinct interventions sites for stakeholders, it is also based on a particular distribution of vigilance among various actors. Residents and building owners are involved only in detection practices.

In New York and San Francisco, the involvement of property owners in graffiti removal has been supported by the municipalities, but these cities also created, in 2005 and 2008 respectively, laws forcing property owners to remove illegal graffiti from their buildings (Kramer, 2010; Shobe and Banis, 2014). In cities devising anti-graffiti policies with such strong involvement of inhabitants, the maintenance of public order is explicitly articulated as the protection of private property. In Paris, by contrast, while owners sometimes remove graffiti themselves, they have not been officially included as active removers in the successive calls for tenders since 2000 , and most graffiti removal workers consider owners to be unqualified and incapable. Hence, graffiti removal is conceived of as a free public service, in which the city residents, barely involved, are the main beneficiaries. Such a distribution of roles is an important feature of the maintenance epistemology at work in Paris. It acknowledges specific competencies and expertise among municipal employees, specialized companies, owners and dwellers, while laying down everyone's responsibilities.

Among the consequences of this distribution, attentiveness towards the presence of graffiti has been largely respecified and organized in a new occupational activity. Graffiti removal has raised challenges regarding not only the development of specific occupations, such as graffiti detectors and removers, planning managers and specialized vehicle mechanics, but also in terms of task definition, recruitment and staff training.

You have to get back into the 2000s context. Specialized in urban cleanliness, we knew how to clean the streets, but we didn't know anything about graffiti removal. Most of the work organization had to be set up. Rounds were designed according to the surfaces and by associating a specific person and a particular vehicle. ... We hired people who were trained as building painters or as stone specialists. These skills are helpful for surface preparation. So these people had a little bit of a job, though. But then they had also to be able to read a map, 
to drive, to move around Paris, to find their way around, and to perform removing techniques.

(Tim, manager of one of the companies, December 24, 2016)

Simultaneously, the implementation of information systems dedicated to the supervision and the reporting of the new activity has been adapted successively. The removal techniques themselves, notably the products that were used, have evolved to provide increasingly covering and resistant paints, or solvents, that preserve walls and comply with environmental standards.

Beyond this renewed attention to unsolicited inscriptions, which has been distributed between city residents and specialized workers, the maintenance of graffiti removal in Paris is also a matter of rhythm. It sets a very specific pace for the 'dance of maintenance' (Denis and Pontille, 2019).

\section{The paces of intervention}

Considering that any minute visual sign of public disorder has to be treated urgently, the 'broken windows' theory is closely related to the definition of particular rhythms for interventions.

In Paris, graffiti detection has been organized as part of a day-to-day practice. In concrete terms, some employees of the contracted companies are dedicated to walk the streets all year long in search of unsolicited inscriptions. Allocated to specific areas in Paris, detectors, as they are called, are provided with maps displaying small parts of their districts. Each detector usually covers all their streets over the course of one week, and then starts again with another map. Finding some graffiti, the detector takes a smartphone and opens a dedicated app to take a picture. They provide detailed information on the graffiti's location, form and accessibility (figure 1):

For each intervention, I generate a file by clicking on 'report a graffiti', then I fill in the different categories: address, intervention times (for shops), type of vehicles (for parking), material characteristics of the surface, suggested intervention technique, etc. Then I take a picture, and I validate. All is directly transmitted and linked to the database. (Jack, graffiti detector, February 16, 2018) 
Figure 1. Reporting graffiti presence (@ J. Denis \& D. Pontille)

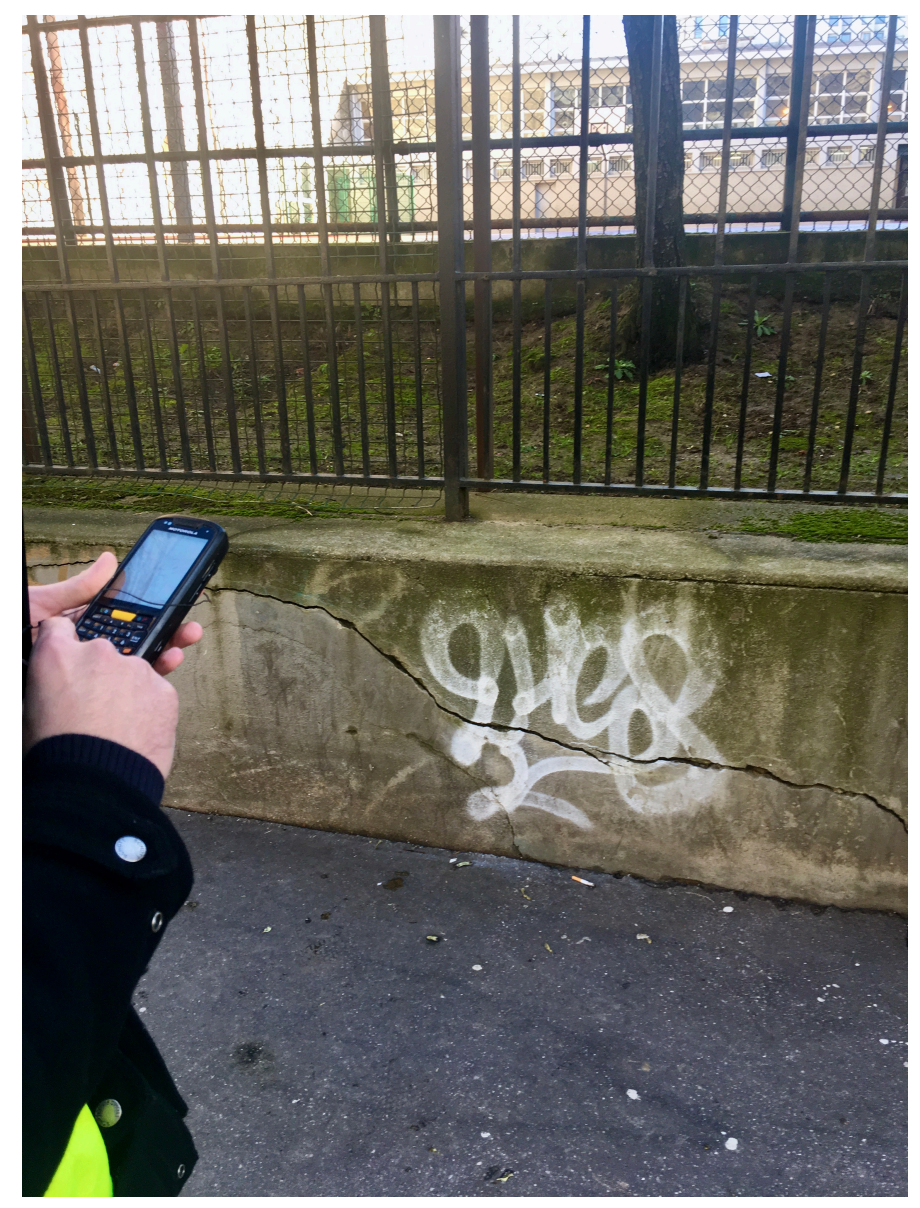

Similar detection activities are carried out by some of the municipal employees, either from the special graffiti removal team or from each Paris arrondissement. They generally take advantage of their displacements in the neighborhoods to watch for and report graffiti to the concerned companies via emails, indicating the street name and providing a picture. Local residents may also report the presence of graffiti, using the toll-free number, the Paris website or the 'InMyStreet' app. Some streets of Paris are therefore travelled daily by several people who meticulously scrutinize façades and urban furniture.

Graffiti removal interventions also take place on a daily basis. They are planned according to a specific schedule, though. The contract signed by the municipality and the contracted companies specifies that interventions take place 'from Monday to Saturday, except on public holidays, in the time slot 7:00 am / 10:00 pm'. In this manner, the noise generated by removal is not expected to unduly disturb residents. But the contract also sets a strict processing time: the removal intervention must come within 10 working days of the date of detection. Reduced from one call for tenders to the next, the response time was 14 days between 2000-2005, 12 days between 2006-2011, and then 10 days from 2012 onwards. The reduced timeframes underline the importance given to the sustained rhythm of detection and intervention.

Another kind of pace is superimposed on the alternation of detection and removal. Every month, mandatory inspections are organized by the graffiti removal municipal team to ascertain the performance of each company. These monthly audits conducted in the streets bring together at least a representative of the graffiti removal city team, a member of the municipal arrondissement, and a manager of the company. Each inspection is conceived of 
as a representative sample of a particular arrondissement. Concretely, a new starting point is randomly selected each time, from which a systematic path is followed over a specified distance: for instance, from a starting point on François Miron Street (figure 2), then the first street to the left, the next to the right, the next to the left, and so on, until an endpoint on the other bank of the Seine. The amount of graffiti presence is collectively recorded and compared to the contractual threshold defined for this area, and if the latter is exceeded, the company is charged a fee. As four companies have been involved in this performancebased market since 2018, such an inspection is accomplished four times a month in Paris.

Figure 2. A randomly selected round for auditing inspection, 28th March 2017 (C J. Denis \& D. Pontille)

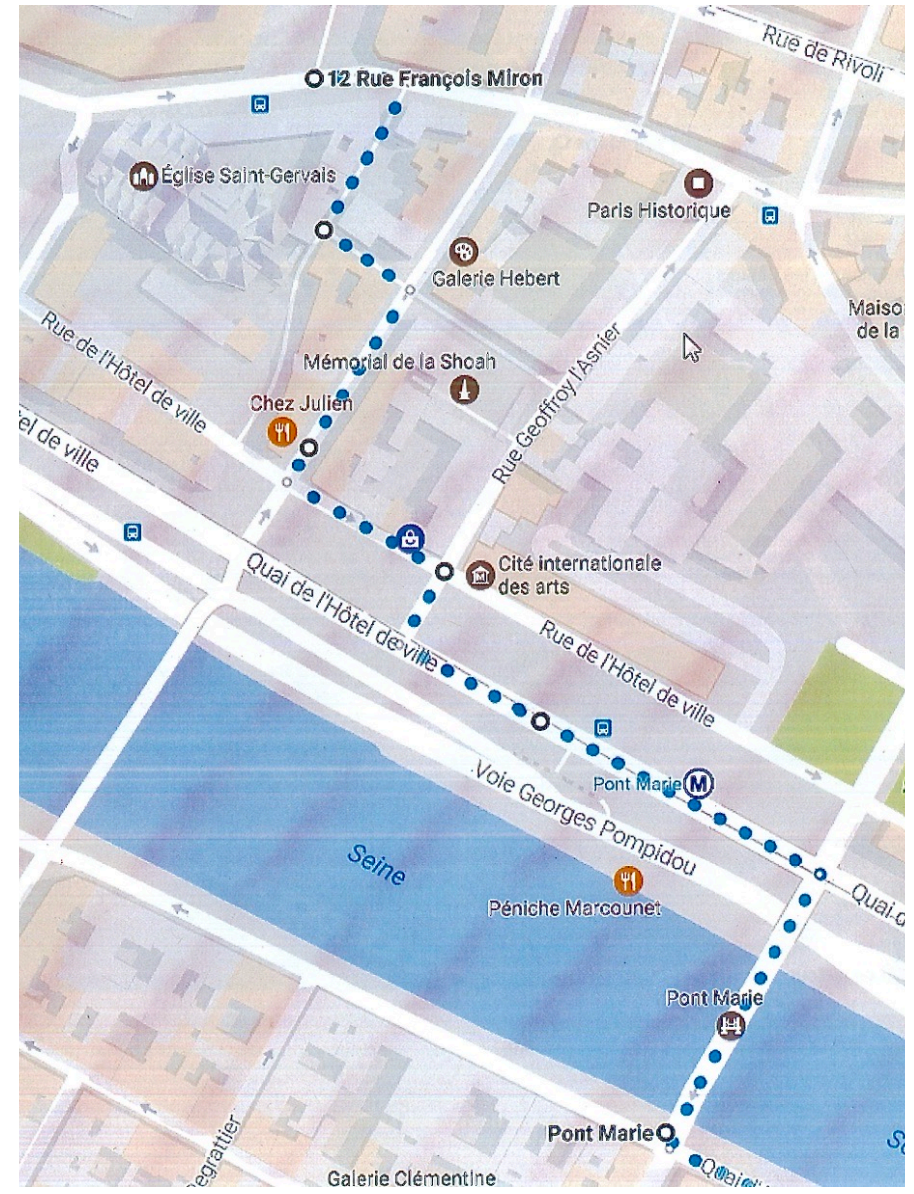

Operating over a longer cycle, a third rhythm is at work every four or five years. Even though the main principles remain the same, each new call for tenders comes with its own adjustments. For instance, there are new entities to be checked and treated (e.g. stickers, some urban furniture), the use of solvents, paints and vehicles has to comply with changing environmental standards, and the design of information systems to plan and report removal work has been gradually adjusted. Moreover, from one public graffiti removal contract to another, the successful companies are different, as are the geographical areas allocated to them. This means that each company must make adaptations to its organization of rounds, its division of labor between graffiti detectors and removers, and the corresponding management staff. Although these organizational changes occur at a slower pace than the previous ones, they are not restricted to the contractual relationship between the municipality and the companies. Each new call for tenders is followed by a transition time that manifests itself in the streets, where the increase in graffiti is sometimes visible. 
These different paces highlight how maintenance epistemics punctuate the daily life of the city through the temporal and spatial distribution of detection and removal activities.

However, these rhythms do not specify what graffiti detection and removal entail in practice. How is the graffiti presence actively managed on a daily basis? What counts for the public order of Paris to be maintained free of graffiti? During our investigation, we identified three main processes at play: measuring surfaces, identifying public expressions and composing with materials.

\section{Measuring surfaces}

In Paris, quantification has been at the core of the graffiti removal program since its very start. The overall objective assigned to the contracted companies has been to maintain the graffiti presence under a maximum threshold of $10 \%$ in every area of the city, regardless of locations and surfaces included in the contract. However, how is graffiti counted? With which measuring instruments? The solution devised by the Paris City Hall understands graffiti in terms of area, measured in square meters. What counts is not the number of instances of graffiti, but the size of the 'graffitied surface'. The 2018 bidding documents specify:

When several graffiti are considered as part of the same graffitied surface, the measurement of the latter will be the sum of the measurements of the simple geometric surfaces surrounding the graffitied surface. (Bidding documents, technical specifications, 2018, p. 10)

This method was inaugurated before the first call for tenders in 1999, when a 'graffiti observatory' was created to measure the extent of graffitied surfaces $\left(240,000 \mathrm{~m}^{2}\right)$. The $10 \%$ maximum threshold of graffiti presence on façades was the result of this inventory, as well as the objective of removing 'graffiti visible and accessible to the public, affixed to a horizontal, vertical or inclined surface, at a maximum height of 4 meters from ground level'.

Daily surface measurement is at the heart of work organization. Like graffiti detectors, each graffiti removal worker starts their intervention by taking a picture of the graffiti and providing detailed information about it in a software through their smartphone. During such a description, the accuracy of the graffiti size stands in three main units $\left(0.10 \mathrm{~m}^{2} ; 0.25 \mathrm{~m}^{2}\right.$ and $0.50 \mathrm{~m}^{2}$ ) that can be added together. At the end of each intervention, a picture of the cleaned surface is added to the file, which is then uploaded to the centralized database of the company.

The graffiti removal municipal team has access to this data in real time, and can produce statistics to be displayed in monthly and annual reports. Since they account for the result of every removal intervention, the measured surfaces provide important information about the performance of each contracted company. The municipality's managers can assess their activity at a glance, for example by comparing the amount of graffitied surfaces removed in a specific area for different given periods of time. As already mentioned, they are also mobilized at the end of each monthly auditing inspection, when the sum of all graffitied surfaces remaining is counted and compared to the required threshold in order to calculate a potential penalty of up to the amount of the excess square meters. In addition, this data can be drawn upon in case of litigation with the municipality or an owner, since it would prove that an intervention has indeed been carried out.

Once aggregated, the measured surfaces are used to draw maps that bring to light the geographic distribution of graffiti in the entire city. A crucial device in the epistemology of 
graffiti removal, these maps give graffiti themselves a specific kind of texture and intelligibility. Through them, graffiti can be apprehended as a spatial phenomenon that is precisely traced, and whose spread can be anticipated. Two indicators are calculated for this purpose: the average quantity of cleaned surface during a certain timeframe for a specific place, and the 'recurrence rate' (after how long a cleaned surface has to be treated again). Such space-based indicators provide precious information to the contracted companies, allowing them to use some custom-made maps to allocate teams and optimize rounds. One company, for instance, regularly use them to identify 'red zones' in each neighborhood, where more workers are needed than elsewhere, and where the pace of interventions is more intense (figure 3).

Figure 3. A map highlighting a "red zone" in a given neighborhood (@ J. Denis \& D. Pontille)

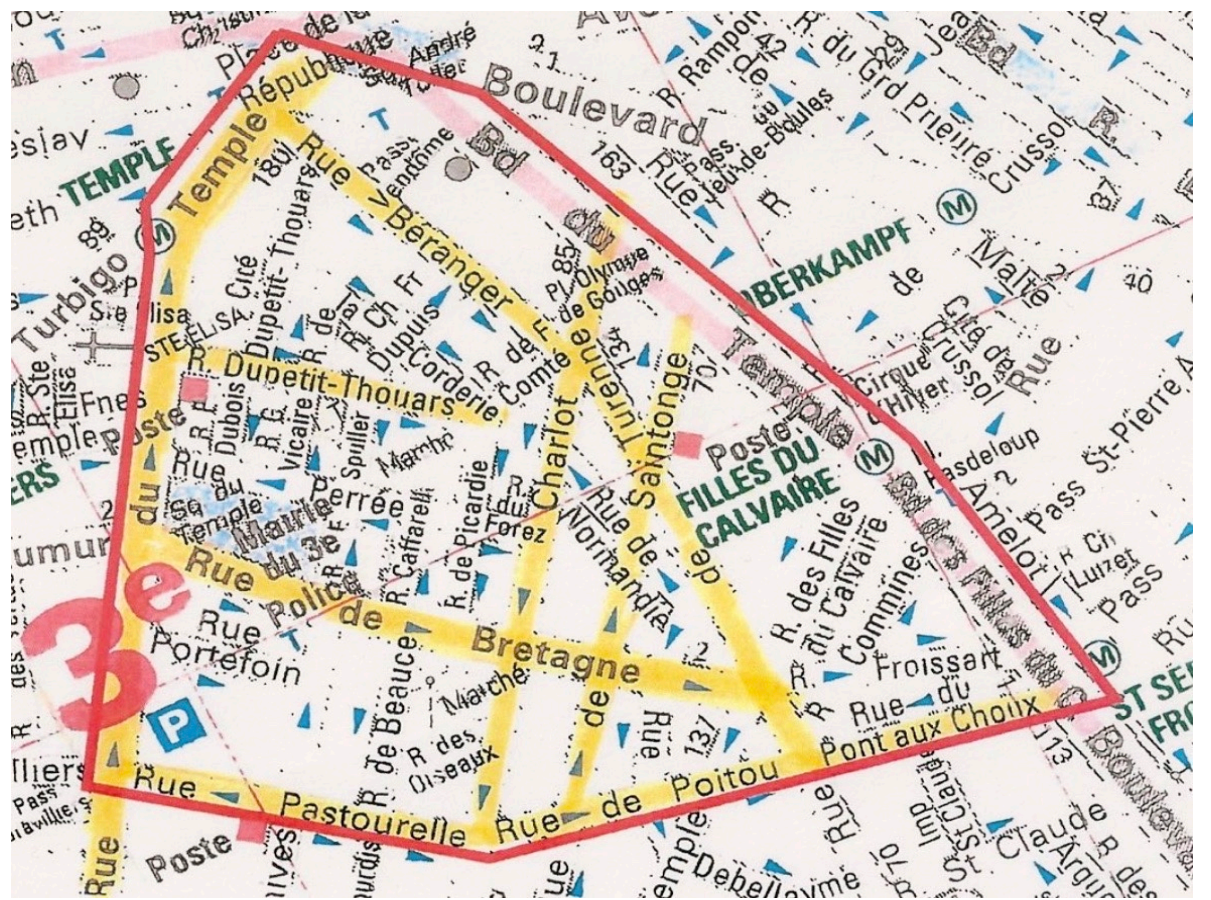

Maps are also a major instrument in the territorialization process at play during the preparation of each new call for tenders. As we mentioned earlier, the city has been progressively divided into areas ('lots'), which work like sub-markets put out to competition with each call for tenders. The sizes of these lots are based on the conditions of their management. Every lot combines several Paris arrondissements, which are divided into intervention zones where a specific residual graffiti threshold is not to be exceeded.

Combined, aggregated and translated into maps, the measurement of surfaces thus participates in making both graffiti a manageable phenomenon and Paris a governable and marketable territory.

But surface measurement also enacts another epistemic operation regarding graffiti. Making sense of graffiti removal in terms of quantified surfaces enacts a very specific definition that holds together the inscriptions and their surfaces. The measurement of twodimensional spaces is based on a commensurability specific to quantification (Espeland and Stevens, 1998; Latour, 1986). Heterogeneous elements are made legible and combinable with one another, and put at the same level. For example, in the statistics produced monthly by each company (figure 4), street furniture is described in twenty-eight categories (e.g. street bin, candelabrum, façade, bollard, etc.) and the treated surfaces are divided into 
eighteen categories (e.g. brick, concrete, glass, plaster, tar, tile, wood, etc.). Once combined and added together, these different elements populating the urban space provide information on the 'total surface area of cleaned surfaces in Paris'.

Figure 4. Statistics of cleaned surface by material, December 2016, lot 1 (@ J. Denis \& D. Pontille).

\begin{tabular}{lrr}
\hline Material & $\begin{array}{c}\text { Quantity } \\
(\mathrm{N})\end{array}$ & $\begin{array}{c}\text { Cleaned } \\
\text { surface }\left(\mathrm{m}^{2}\right)\end{array}$ \\
\hline Concrete & 7 & 7,75 \\
Wood & 99 & 175,25 \\
Brick & 2 & 1,50 \\
Tiles & 1 & 1,00 \\
Rendering & 5 & 22,50 \\
Tar & 18 & 143,75 \\
Granite & 6 & 7,00 \\
Marble & 20 & 27,25 \\
Metal & 379 & 755,25 \\
Mineral & 3 & 5,25 \\
Painted wall & 568 & 1305,75 \\
Cinder blocks & 1 & 3,00 \\
Stapled stone & 15 & 26,25 \\
Dressed stone & 77 & 108,25 \\
Plastic & 52 & 49,75 \\
Plaster & 1 & 0,50 \\
Metal curtain & 133 & 675,25 \\
Glass & 15 & 45,25 \\
\hline Total & 1402 & 3360,50 \\
\hline & &
\end{tabular}

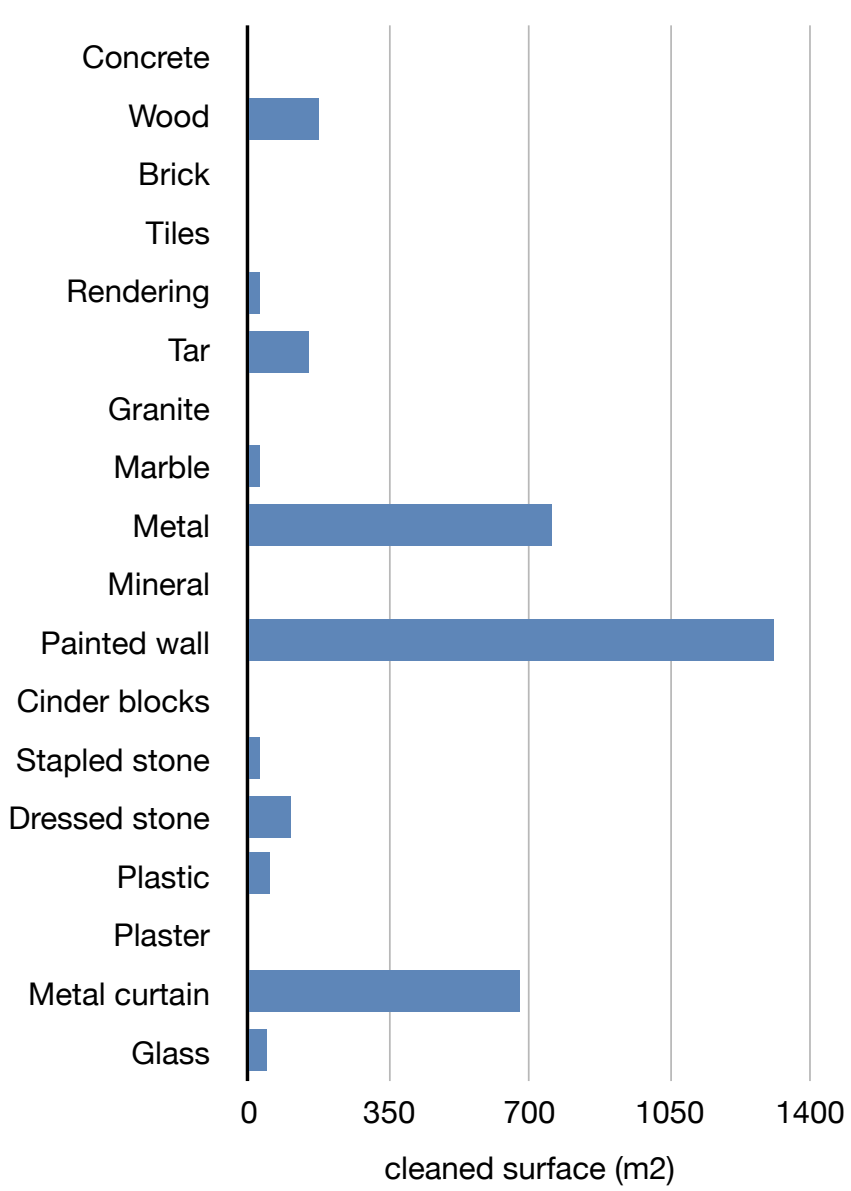

However, this aggregation is far from exhaustive. Although the municipal by-law issued in October 1999 made it possible to intervene on a considerable number of Paris façades, many remain outside the maintenance interventions, due to their legal status. This is notably the case for those belonging to large private or public companies, which retain responsibility for removing graffiti from their buildings and furniture. More generally, numerous façades and roof walls remain outside the scope of interventions, even though its maximum height has increased from 3 meters (from 2000 to 2011) to 4 meters (from 2012 onwards). Although the purpose of graffiti removal is to treat all surfaces of the city, the Paris policy is fragmentary.

The ways of calculating the relevant surfaces are themselves discussed. During the monthly auditing inspections, for instance, the definition of what counts as a cleaned surface, and how it is measured, is regularly adjusted according to the path followed by the participants, whose common perception of graffiti is the result of the modalities of their wandering (Gibson, 1979). When, at the end of the inspection, unnoticed graffiti are found by following the same path back to the vehicles, no participants consider it a problem. In other occasions, expected surfaces to be counted are not that obviously accessible. The workers 
sometimes have to negotiate with inhabitants or owners. Occasionally, a shopkeeper even physically opposes any intervention, even without having signed the appropriate discharge. Finally, some surfaces do not always count. Metal curtains count as surfaces only when they are down, and they disappear as a 'graffitied surface' as stores open. The 2018 bidding documents specify that other surfaces, notably of porous materials, can be excluded from regular maintenance work, classified as 'non-cleanable surfaces' after several interventions.

As a maintenance practice, the Paris graffiti removal program transforms some parts of the urban reality into surfaces to be calculated and aggregated. Graffiti is turned into accounting units that can be easily tracked, reported and put into temporal and spatial series. The presence and absence of the disorders of which it is considered to be a sign can be precisely monitored and anticipated. Reducing graffiti to a quantified surface is, however, one option among others, one that leaves open its expressive properties.

\section{Identifying public expressions}

What exactly is graffiti? More precisely, what counts as graffiti in the Paris removal policy? In the call for tenders, a very extensive definition of graffiti is provided that lies in the mere association of a surface and a graphic inscription. According to the 2018 bidding documents,

Graffiti is considered to be any graphic inscription made on a surface using stained agents of any kind, regardless of the method of application. Any spillage of paint, whether accidental or deliberate, falls within this definition of graffiti. (Bidding documents, technical specifications, 2018, p. 5)

If this understanding of graffiti were the only one in place, any trace of graphic inscription would have to be removed from the building façades. This is, of course, not the case. In addition to this maximalist definition, more categories are specified in the terms of contracts and calls for tenders, and some mundane judgments and 'categorical work' (Bowker and Star, 1999) are also at stake when graffiti detectors or removers consider the public inscriptions, their meanings, shapes and colors.

A first characterization, which reiterates a recurring dilemma (Austin, 2001; Cresswell, 1992; McAuliffe and Iveson, 2011), draws a distinction between authorized graffiti, often called 'artworks' or 'murals', and everything else. This distinction is made possible by the identification of the ones that should not be removed. A list of walls and addresses, with pictures, is regularly updated by local authorities and sent to the contracted companies. Designating exceptions, this list reports a series of inscriptions that are excluded from the contractual routine of maintenance work. Occasional requests also occur from municipal teams who may decide to preserve a piece to their liking. Such specific demands sometimes comes with a picture (figure 5), where the graffiti that have to be removed are clearly distinguished ('remove what is surrounded' written at the bottom) from the 'mural' that should remain intact ('do not touch the artwork' specified at the top right). In these cases, removing graffiti both consists in preserving the façade image and restoring the artwork. 
Figure 5. Making a clear distinction between graffiti and artwork (@ J. Denis \& D. Pontille)

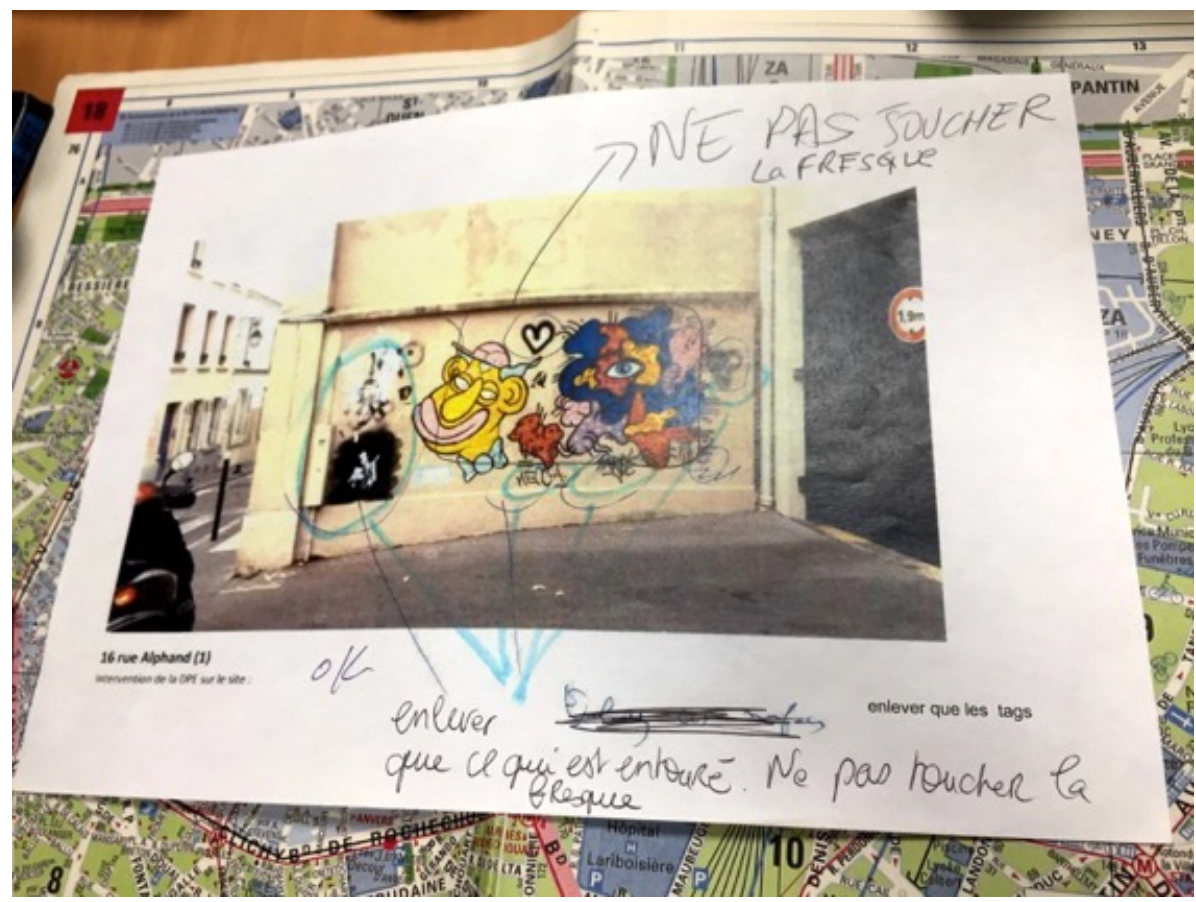

However, the difference between authorized artworks to remain and graffiti to be removed is not resolved once and for all by the circulation of lists and official requests. It is also at play during day-to-day interventions, which may give rise to doubts, or to judgments on the spot. As we were shadowing the graffiti removal workers, they regularly explained to us why this or that inscription should not be removed, mobilizing situated criteria such as 'it's clear that this inscription is intended to be here' or 'this one is signed'. These considerations combine aesthetic and material assessments to know how far the graffiti is part of an intentional process, negotiated with the owner. If so, its removal can be problematic and issue a litigation. For example, in front of a metal curtain with an imposing graffiti, John specifies:

When it's filled like that, often it's because it is intentional, the shopkeeper wants to keep it.... Anyway, with a full curtain like this, as soon as we have a doubt, we take the picture and we discuss it with our managers. (Andrew, graffiti removal worker, March 15, 2017)

Neither on the official list, nor the object of a specific request from a member of the municipal team, a graffiti can therefore, for a time at least, escape the relentless march of the 'broken windows' thesis. This first characterization of expressiveness thus makes the tension between art and vandalism a recurrent, located and distributed oscillation.

Another crucial characterization refers to a very different aspect of expressiveness. Drawing on an 1881 law dedicated to the freedom of press and the Article 322 of the Criminal Code on damage to property (Vaslin, 2017), the municipal contract for the graffiti program clearly distinguishes any graffiti from those that are 'offensive, pornographic or prejudicial to public order'. Such categorization calls for a particularly demanding contractual framework. Whereas all graffiti have to be removed within ten days after their detection, the contracted companies are compelled to remove offensive ones within three hours, 24/7. Graffiti are understood here as speech acts and their removal is part of a real 'politics of the 
performative' (Butler, 1997), which places the dangerous nature of some written words at the root of work organization. ${ }^{2}$

Despite the urgency it brings to the rhythm of interventions, the characterization of offensiveness is ambiguous: Though most graffiti do not raise any doubts, some may appear equivocal or may remain indecipherable for a time. For example, during our fieldwork we were told a worker came back from his daily round explaining that he had found a lot of graffiti from 'ACAB'. There were so many instances that he didn't have time to remove them all. His manager promptly retorted that 'ACAB' was not a writer's name, but an acronym that actually meant 'All Cops Are Bastards', and was thus an offensive inscription that had to be removed immediately. Since then, a poster has been displayed in the office, reminding everyone that 'ACAB' should not be treated as just another graffiti tag. The epistemology of the Paris graffiti removal program is thus grounded in adjusted and nuanced categorizations, linked to a $19^{\text {th }}$-century policy against 'scriptural delinquency' (Artières, 2017).

Parallel with quantified and geographical units, graffiti are perceived as graphic manifestations with varied aesthetic meaning, forms and colors, made of words, political slogans or drawings (humorous, erotic ...) that are more or less evocative, provocative or offensive. Here, graffiti are not comprehended as a continuous phenomenon but as discrete instances, namely as public inscriptions, and examined for their contrasted expressiveness.

\section{Composing with materials}

The actual removing of graffiti remains to be done. Far from being a mechanical implementation of theoretical and managerial principles, this practical operation, through its subtleties, directly participates in the continuous shaping and cultivation of maintenance epistemics.

Removing graffiti is a tricky affair whose success stems from the implementation of four main removal techniques: diverse solvents, high-pressure water, sandblasters and paint. In any case, these techniques must be used with care, or the integrity of the surface to be cleaned may be irremediably damaged. Graffiti removal demands a careful consideration of materials.

This aspect is crucial in the contract signed by the contracted companies. To prevent failures resulting from reactions between materials, some removal techniques are explicitly banned for some surface matters. More precisely, a table in Annex 1 of the technical specifications in the 2018 bidding documents lists the techniques that are inappropriate with façades made of porous (e.g. 'polished stone and marble, brick, tiles and ceramics, raw wood and varnished') and non-porous materials (e.g. 'painted metal and plaster, plastics, plexiglass'). Any damage to the façade due to non-compliance with these instructions will result in the company's paying restoration costs.

The focus on materials' associations is also obvious in the streets. Once they get out of their van, the workers do not just stare at the graffiti they must remove. Instead, for each intervention, they approach the façade and stretch their hands out to touch it (figure 6). This inaugural gesture tells how much the attention to materials goes beyond sight. Touching both the graffiti and the surface on which it is written, the workers simultaneously feel their

\footnotetext{
2 In New York City, the exponential growth of graffiti in the 1970s also gave rise to prioritizing removal interventions according to graffiti content: first 'obscenity', then 'racist', and 'the innocuous stuff' (Prial, 1972).
} 
respective material properties, and assess their mutual relationships. This gesture, they told us, informs the choice of an appropriate removal technique.

It is essential to look and touch closely. With porous material, the graffiti migrates within the stone very quickly, it is almost impossible to remove it entirely. And the stone itself is extremely fragile. If you use high-pressure water or a sandblaster, you carve into the wall, really. (Andrew, graffiti removal worker, March 15, 2017)

Although some principles drive the use of removal techniques and products, each intervention is a material challenge that starts with this physical contact. The gesture is all the more striking because it concerns an entity - such as a stone building façade - that may seem to be one of the most solid and immutable components of cities. The graffiti removal workers approach façades as fragile and easily damaged entities.

Figure 6. Touching the graffitied surface (@ J. Denis \& D. Pontille)

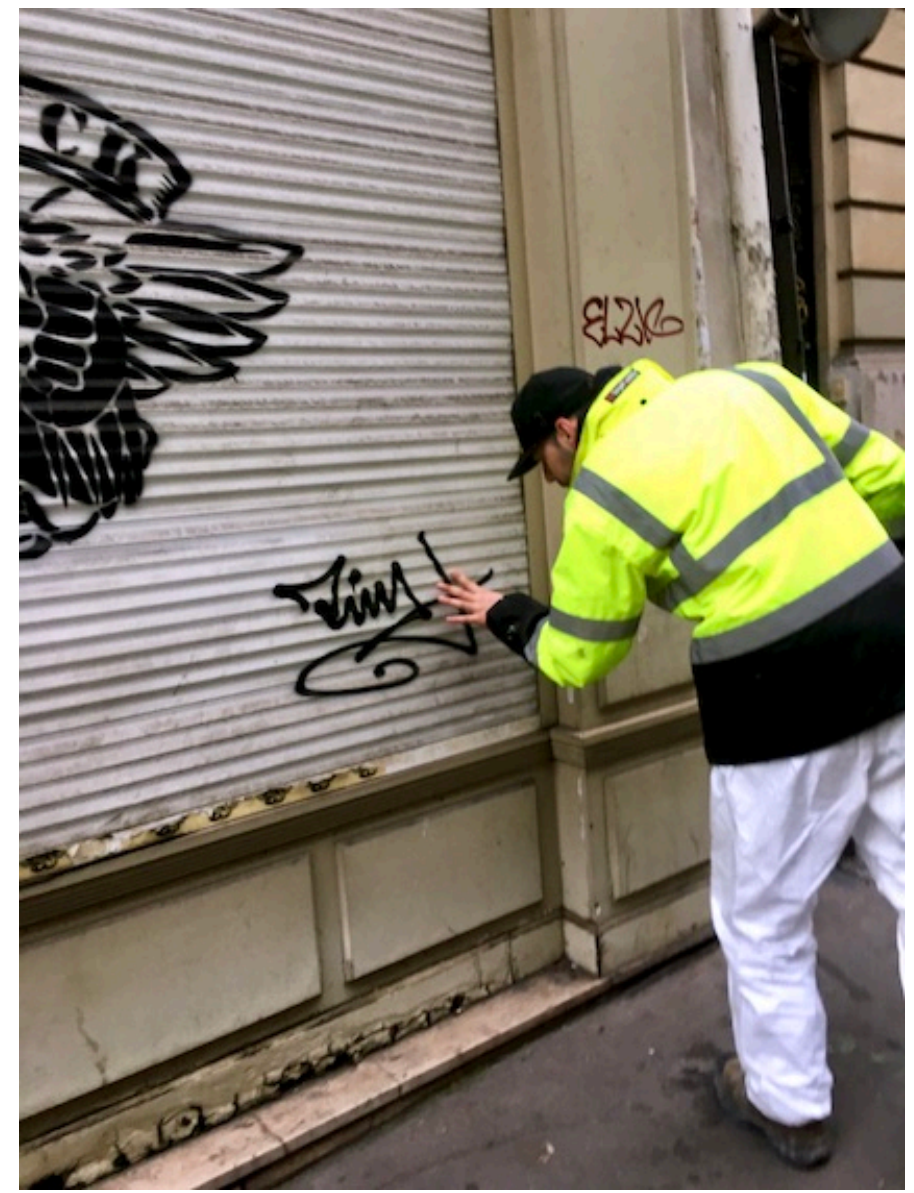

An even more fine adjustment is at stake. By touching, the workers also anticipate the practical conditions for implementing the chosen removal technique. For instance, they consider the consistency of the paint covering the graffitied surface and its reaction to the solvent. This preliminary assessment guides them both towards the dose of product to be applied and the rhythm to be adopted with sponges and rags.

Most paints do not resist the solvent. If the chemical product acts too hard or if the paint on the surface is not strong enough, the latter will also be affected. It can work on boiled paints, which have been industrially applied. Even in this case, you must go very fast, to be careful not to let the product act too much. (Randy, graffiti removal worker, March 15, 2017) 
Beyond the evaluation of the materials composing both the graffiti and the surface, the physical contact makes the workers sensitive to the resistance of materials and helps them to anticipate what treatments the façade is likely to withstand.

What this systematic inaugural gesture tells us is that graffiti removal lies in the encounter between materials of the graffiti, the façade and the intervention, whose reactions are uncertain and erratic. Like other maintenance practices, it consists in an exploratory attitude that foregrounds materials, in order to investigate their composition in looking at closely, touching, hearing and smelling (Dant, 2010; Henke, 2000). Exploring the situated enactments of the material properties of graffiti, surfaces and removal techniques, the workers pay particular attention to materials' associations. They know that the success of their interventions is never a foregone conclusion.

Among possible failures, two are particularly revealing of the material features of the maintenance. First, if the form of the graffiti persists, despite having been stripped of ink or paint, the workers leave what they call a 'ghost'. The graffiti shape remains noticeable, if not semi-legible (figure 7, left). Second, covering a graffiti with paint, apparently the simplest technique, comes with the challenge of finding the shade that exactly matches the color of the surface. When they manage to obtain it, the workers still have to find a way to delimit the zone of their intervention, so that the new coat of paint will, according to the 2018 bidding documents, 'maintain a homogeneous aesthetic appearance of the façade'. Otherwise, they would produce what they call a 'cleanness stain' that undermines the intervention (figure 7, right). Thus, removing graffiti is not enough in itself. The resulting production of a 'ghost' or a 'cleanness stain' would still disrupts the material and aesthetic harmony of the public order.

Figure 7. A "ghost" and a "cleanness stain" (๑ J. Denis \& D. Pontille)

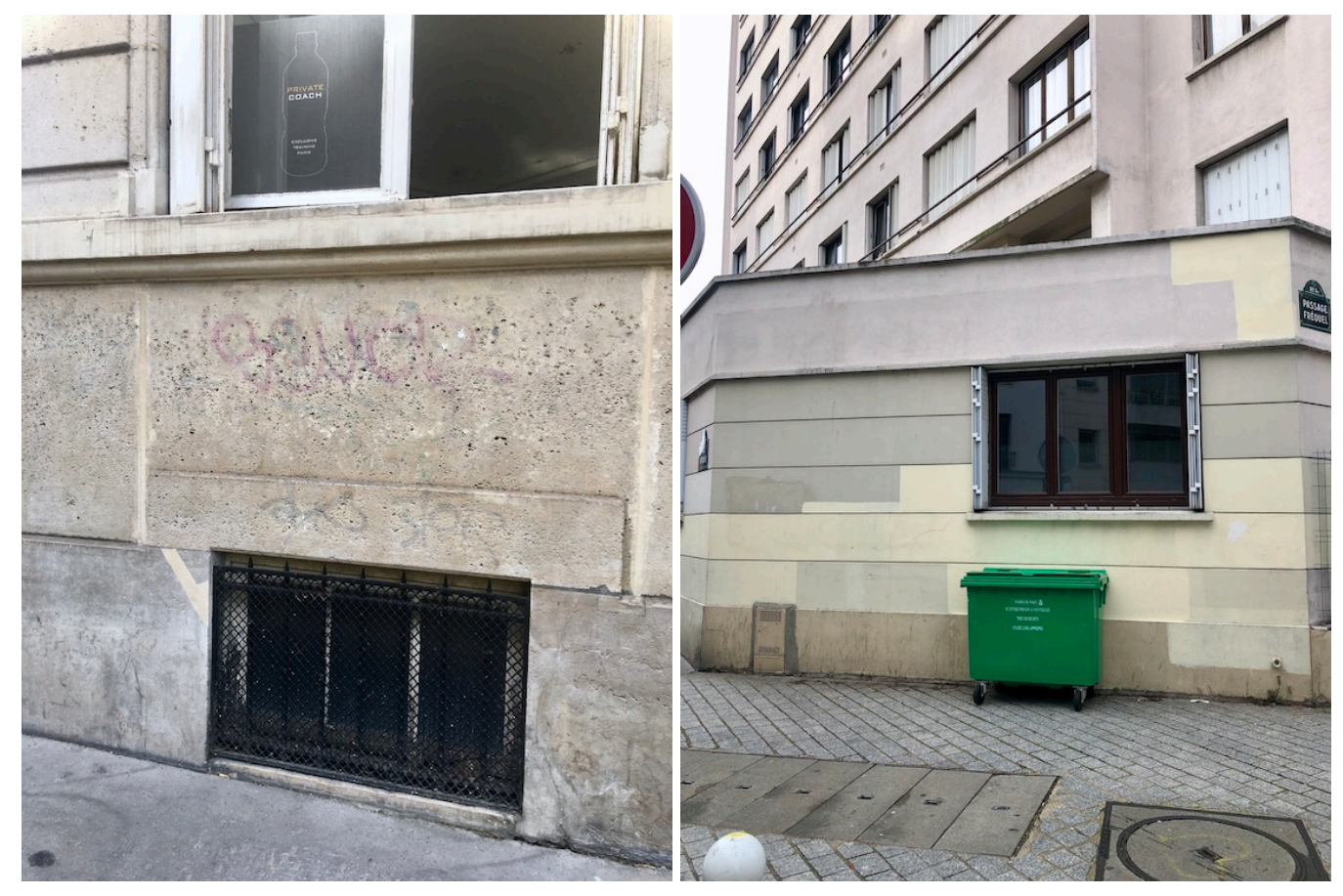

Neither the graffitied surface measurements nor the judged expressiveness of written inscriptions make it possible to know what, in practice, must be removed or added for a graffiti to be considered removed. This uncertainty involves 'composing with' a large number of components that interact with one another. While some are more or less 
recognizable, others are only identifiable after physical contact and situated tests. During each graffiti removal intervention, the workers make themselves sensitive to the 'ecology of materials' (Ingold, 2012) of urban inscriptions, made of concrete, plaster, bricks, water, sand, stones, wood, marble, chemical solvents, mural paint, graffiti paint, ink, etc. Following this 'matter-flow' (Deleuze and Guattari, 1987: 451), the difference between the elements that make up the graffiti, the surface and the removal products is unclear, and lies in the continually emergent process of their becoming. Moreover, their respective boundaries are uncertain and fragile. Consequently, as graffiti removal lies in composing with material modulations, it is inseparable from the material transformation and the potential aesthetic deterioration of the façade.

\section{Conclusion}

In this article, we have investigated graffiti removal in Paris as a specific form of maintenance of urban order which is performed through daily interventions. Starting from the 'broken windows' thesis, a theoretical and political doctrine first formulated in the US, the graphic order of the city is considered the first crucial step towards the public order maintenance, and is achieved through direct encounters with inscriptions on building façades. We have described the assemblage of contractual documents, legal rules, procedures, categories, information infrastructures, removal techniques, tools, situated gestures and materials that are at play in this seemingly trivial graffiti removal policy. This maintenance assemblage, we argue, enacts and cultivates a particular epistemology of public order.

Entirely focused on visual signs, the 'broken windows' thesis makes certain things matter in the midst of a vibrant and crowded urban reality. It identifies certain kinds of phenomena as traces of disorder and states that these signs of disruption, as tiny they maybe, must be treated systematically in order to prevent the acceleration of decay and eventually avoid a major collapse. This model performs a 'territorialization', in the sense of Deleuze and Guatari: The epistemology of public order it articulates extracts a 'territory ... made of decoded fragments of all kinds, which are borrowed from the milieus but then assume the value of "properties"' (Deleuze and Guattari, 1987: 504).

Such territorialization goes through a variety of physical processes and has very concrete consequences. The signs apprehended as threats of public order, such as graffiti, are mundane, and are known to appear on the city walls on a daily basis. Their removal has to be done urgently and continuously. In the case of Paris, the territorialization at play in the graffiti removal program goes through a multifaceted characterization and a composite treatment of the city's building façades. Façades have been legally transformed to become daily accessible to contractors, are calculated as quantified surfaces made commensurable through specific measurement tools and practices, are apprehended as sites of distinct forms of public expression, and are looked at and handled as fragile aggregations of heterogeneous materials. Each of these dimensions intertwines practical and knowledge issues that everyone deals with, from the municipality's team supervisor to the workers and the contractors' managers.

If we had stuck with the official texts and principles of the doctrine, we would have been tempted to describe the Paris program as an abstract disciplinary framework through which, to maintain the city pristine and cohesive, graffiti is thought of as an invasive phenomena to be blindly eradicated from façades, which are defined as stable and uniform surfaces. Such 
a perspective sheds light on the preservationist approach that drives the program, and emphasizes the ontological implications of maintenance. The graffiti removal program binds together intertwined definitions of graffiti, building façades, urban reality and public order. Yet, because it sticks to a very limited set of documents, and stops at the doorsteps of the municipality's offices, this sole account is limited.

The epistemography (Dear, 2001) we have conducted, through which we have unfolded the places, tools, materials, vocabulary and bodies that are directly connected to the official documents and the theoretical texts, helps to provide a more comprehensive understanding of this urban maintenance.

Yet, this approach should not suggest that all the elements of this heterogeneous assemblage are equal, that they have the same effects, or that they are all equitably acknowledged. For example, surface measurement takes an important part in the management of the teams, the accountability of the companies and even the territorialization of the city. How materials and their composition are apprehended, from the technical specifications to the situated knowledges and gestures of maintenance workers, has less dramatic consequences on management and territorial governance, while is of crucial importance in the material treatment of each façade. Moreover, the maintenance epistemology of graffiti removal is not the only one at work in the municipal management of all graffiti matters. Although the legal and police struggle against graffiti may rely on some features of the assemblage we have described (in particular the use of statistics and maps), its own methods and knowledge are focused on the individual graffiti writer whom is significantly absent in the maintenance epistemology. Similarly, the numerous initiatives that have flourished in cities all over the world to officially promote graffiti in certain conditions and forms come with their own ways of dealing with and defining façades, urban reality, public order and graffiti.

We want to highlight three main aspects. First, the maintenance epistemology at play in graffiti removal draws on inquiries, doubts and improvisations. Is this graffiti a public offense? Will this stone resist the foreseen removal technique? Why doesn't the paint behave as expected? Even though the things that are maintained or taken care of are clearly defined in numerous documents, even though the ways to apprehend them and the methods to treat them are detailed in procedures and contracts, in numerous situations (from meetings in the contractors offices, to the monthly auditing inspections performed with the municipal team and, of course, to the daily interventions on the façades) adjustments are made, skills are refined, and knowledge is cultivated and enriched. What is graffiti? What is the city? What is public order? These questions are recurrently enacted during the daily inquiries of which maintenance is made.

Second, as 'disciplinary' as it is, the territorialization process at play is being subjected to many overflows and mutations. Graffiti evolves constantly. Graffiti writers adjust their techniques and sites of operation, and new kind of inscriptions appear on the building façades (for example, memorials flourished after terrorist attacks, and activists have recently used collages to denounce how feminicides were treated). Building façades themselves change, as trends in architecture or international standards and norms promote the use of new types of materials, some of which present unprecedented challenges for removal techniques, skills and knowledge in place.

Third, and most importantly, the maintenance at play is transformative. As every preservationist program, graffiti removal in Paris faces a dilemma: The building façades have to be freed from graffiti as if they have never been altered, but this can only be performed 
through interventions that may cause them to undergo further degradation. As Jones and Yarrow (2013) have also shown, most of this tension - which is crystallized in the principle of 'minimal intervention' in heritage conservation international charters - is dealt with on site, throughout the negotiated material encounter between the maintenance workers and the buildings themselves. Unlike heritage preservation, though, in graffiti removal the dilemma does not arise in the temporal context of exceptional and spectacular campaigns that buildings undergo once every century. It transpires in each mundane intervention and is a day-to-day feature of such a maintenance.

And yet, every removal intervention is inevitably the source of mutations. Graffiti is not an autonomous object that could simply be removed from an independent surface that would be thus brought to a 'previous' state. Many elements that constitute both the graffiti and the façade are removed in the process, on purpose or not (paint, brick, concrete, cement, plaster, varnish). Simultaneously, numerous components, from materials (chemical solvents, sand, paints) to shapes (ghosts or cleanness stains), are added to the city; on its façades, but also in the sewers in which surplus and residual materials are pushed after each intervention (Shaw, 2014). Even when cultivating a preservationist stance, maintenance cannot escape from the becoming of the things whose stability it strives to ensure. Far from boiling down to the infinite loop of a binary cycle in which each inscription is simply followed by its erasure, the public order such maintenance constantly enacts and reenacts comes into existence through transformative iterations. Maintaining a graffiti-free city means having an army of workers in the streets every day, who constantly alter the façades, just as graffiti writers and their inscriptions did before their interventions, and surely will after them.

\section{Acknowledgements}

We warmly thank every person (from managers at the Paris municipal cleanliness and water department to technical managers and graffiti removal teams in contracted companies) who agreed to share with us their experience and practical expertise, and to be shadowed during their working days. We are also very grateful to the three anonymous reviewers for their insightful suggestions and generous feedback.

\section{References}

Akrich M (1992) The de-scription of technical objects. In: Bijker WE and Law J (eds) Shaping Technology/Building Society. Studies in Sociotechnical Change. Cambridge: MIT Press, 205-224.

Andron $S$ (2018) The right to the city is the right to the surface: A case for a surface commons (in 8 arguments, 34 images and some legal provisions). In: Brighenti AM and Kärrholm M (eds) Urban Walls. Political and Cultural Meanings of Vertical Structures and Surfaces. London: Routledge, 191-214.

Artières $P$ (2017) Policing writing in the city, 1852-1945: The invention of scriptural delinquency. In: Lyons $\mathrm{M}$ and Marquilhas $\mathrm{R}$ (eds) Approaches to the History of Written Culture: A World Inscribed. London: Springer, 183-201.

Austin J (2001) Taking the Train: How Graffiti Art Became an Urban Crisis in New York City. New York: Columbia University Press.

Barnes J (2017) States of maintenance: Power, politics, and Egypt's irrigation infrastructure. Environment and Planning D: Society and Space 35(1): 146-164. 
Bowker GC and Star SL (1999) Sorting Things Out: Classification and Its Consequences. Cambridge: MIT Press.

Brand S (1994) How Buildings Learn: What Happens After They're Built. New York: Viking Penguin.

Butler J (1997) Excitable Speech: A Politics of the Performative. New York: Routledge.

Callicott JB and Nelson MP (eds) (1998) The Great New Wilderness Debate. Athens:

University of Georgia Press.

Castleman C (1982) Getting Up: Subway Graffitti in New York. Cambridge: MIT Press.

Cresswell T (1992) The crucial 'where' of graffiti: A geographical analysis of reactions to graffiti in New York. Environment and Planning D: Society and Space 10(3): 329-344.

Dant T (2010) The work of repair: Gesture, emotion and sensual knowledge. Sociological Research Online 15(3): 97-118.

Dear P (2001) Science studies as epistemography. In: Labinger $\mathrm{J}$ and Collins $\mathrm{H}$ (eds) The One Culture? A Conversation about Science. Chicago: University of Chicago Press, 128-141.

Deleuze G and Guattari F (1987) A Thousand Plateaus: Capitalism and Schizophrenia, 2nd ed. Minneapolis: University of Minnesota Press.

Denis J and Pontille D (2015) Material ordering and the care of things. Science, Technology \& Human Values 40(3): 338-367.

Denis J and Pontille D (2017) Beyond breakdown: Exploring regimes of maintenance. Continent 6(1): 13-17.

Denis $J$ and Pontille D (2019) The dance of maintenance and the dynamics of urban assemblages. The daily (re)assembling of Paris subway signs. In: Strebel I, Bovet A, and Sormani P (eds) Repair Work Ethnographies. Revisiting Breakdown, Relocating Materiality. Palgrave MacMillan, 161-185.

Denis J and Pontille D (2020) Why do maintenance and repair matter? In: Blok A, Farías I, Roberts C, (eds) The Routledge Companion to Actor-Network Theory. London:

Routledge, 283-293

Espeland W and Stevens M (1998) Commensuration as social process. Annual Review of Sociology 24(1): 313-343.

Ferrell J (1996) Crimes of Style: Urban Graffiti and the Politics of Criminality. Boston: Northeastern University Press.

Garfinkel H (1967) Studies in Ethnomethodology. Englewood Cliffs: Prentice-Hall.

Gibson JJ (1979) The Ecological Approach to Visual Perception. Hillsdale: Lawrence Erlbaum Associates.

Glazer N (1979) On subway graffiti in New York. Public Interest 54(3): 3-11.

Goffman E (1959) The Presentation of Self in Everyday Life. New York: Anchor.

Graham S and Thrift N (2007) Out of order: Understanding repair and maintenance. Theory, Culture \& Society 24(3): 1-25.

Henke CR (2000) The mechanics of workplace order: Toward a sociology of repair. Berkeley Journal of Sociology 44: 55-81. 
Henke CR (2017) The sustainable university: Repair as maintenance and transformation. continent. 6(1): 40-45.

Ingold T (2012) Toward an ecology of materials. Annual Review of Anthropology 41(1): 427-442.

Jackson SJ (2014) Rethinking Repair. In: Gillespie T, Boczkowski P, and Foot K (eds) Media Technologies: Essays on Communication, Materiality and Society. Cambridge, MA: MIT Press, pp. 221-240.

Jones S and Yarrow T (2013) Crafting authenticity: An ethnography of conservation practice. Journal of Material Culture 18(1): 3-26.

Kelling GL (1991) Reclaiming the subway. City Journal 1(2): 17-28.

Knorr-Cetina K (1981) The Manufacture of Knowledge. An Essay on the Constructivist and Contextual Nature of Science. Oxford: Pergamon Press.

Kramer R (2010) Moral panics and urban growth machines: Official reactions to graffiti in New York City, 1990-2005. Qualitative Sociology 33(3): 297-311.

Kramer R (2012) Political elites, 'broken windows', and the commodification of urban space. Critical Criminology 20(3): 229-248.

Kramer R (2017) The Rise of Legal Graffiti Writing in New York and Beyond. New York: Palgrave Macmillan.

Latour B and Woolgar S (1979) Laboratory Life: The Social Construction of Scientific Facts. Beverly Hills: Sage.

Latour B (1986) Visualisation and cognition: Drawing things together. Knowledge and Society: Studies in the Sociology of Culture and Present 6: 1-40.

Law J (1994) Organising Modernity. Social Ordering and Social Theory. Oxford: Blackwell.

McAuliffe C and Iveson K (2011) Art and crime (and other things besides ... ):

Conceptualising graffiti in the city. Geography Compass 5(3): 128-143.

Prial FJ (1972) Subway graffiti here called epidemic. The New York Times, February 11: 39.

Puig de la Bellacasa M (2012) 'Nothing comes without its world': Thinking with care. The Sociological Review 60(2): 197-216.

Ross Jl (2016) Routledge Handbook of Graffiti and Street Art. London: Routledge.

Shaw R (2014) Cleaning up the streets: Newcastle-upon-Tyne's night-time neighbourhood services team. In: Graham S and McFarlane C (eds) Infrastructural Lives: Urban Infrastructure in Context. Abingdon: Routledge, 174-196.

Shobe $\mathrm{H}$ and Banis D (2014) Zero graffiti for a beautiful city: The cultural politics of urban space in San Francisco. Urban Geography 35(4): 586-607.

Smith D (1985) The truth of graffiti. Art \& Text 17: 85-95.

Stewart M and Kortright $C$ (2015) Cracks and contestation: Toward an ecology of graffiti and abatement. Visual Anthropology 28(1): 67-87.

Strebel I, Bovet A and Sormani P (eds) (2019) Repair Work Ethnographies: Revisiting Breakdown, Relocating Materiality. London: Palgrave MacMillan.

Vaslin J (2017) Esthétique propre. La mise en administration des graffitis à Paris de 1977 à 2017. PhD thesis, Université Lyon 2, Institut d'études politiques, Lyon, France. 
Wilson JQ and Kelling GL (1982) The police and neighborhood safety: Broken windows. The Atlantic Monthly 249(3): 29-38.

Woolgar S and Neyland D (2013) Mundane Governance: Ontology and Accountability.

Oxford: OUP Oxford.

Young A (2010) Negotiated consent or zero tolerance? Responding to graffiti and street art in Melbourne. City 14(1-2): 99-114.

Yurchak A (2015) Bodies of Lenin: The hidden science of communist sovereignty.

Representations 129(1): 116-157. 